\title{
Strength Computation of Bearing Test Station
}

Milan Sapieta ${ }^{1}$, Martin Svoboda ${ }^{2}$

${ }^{1}$ Faculty of Mechanical Engineering, Univerzity of Zilina. Unierzitna 1, 01026 Zilina. Slovak Republic. E-mail: milan.sapieta@fstroj.uniza.sk,

${ }^{2}$ Faculty of production technology and management of Jan Evangelista Purkyně University in Ústí nad Labem, Na Okraji 1001, Czech Republic. E-mail: svoboda@fvtm.ujep.cz

The test station is used to determine the fatigue of bearings in passenger cars. The influence of prestressing or axial clerance, the reliability of the locking elements for the axial adjustment, the quality of the seating of the outer ring and the change in the type, quantity or distribution of the lubricant can also be examined. The test station consists of a test unit for the simultaneous testing of two test bearings. The misalignment of the wheel contact point and the center of the bearing is fixed by means of mountable parts. The test bearings are clamped between the flanges at both ends of the test shaft, which is supported by two auxiliary bearings. The numerical simulation with finite element method (FEM) deals with the analysis of the bearing test station, which will be loaded by axial and radial loads.

Keywords: test station, bearing, FEM analysis

\section{Introduction}

In mathematical modeling of engineering tasks (in the mechanics of a flexible body), complex, until then unsolvable systems of ordinary or partial differential equations arose. This has led to the need to develop numerical, computer-based methods to address this problem. Mathematics (R. Courant), physicists (J. L. Synge) and engineers (J. H. Argyris and S. Kelsey) have started to develop FEM (finite element method). Significant early publications from the beginning of the development of the FEM were published by J.H. Argyris, O. C. Zienkiewicz and Y. K. Cheung. The name of the method was determined by R. W. Clough. The rapid development of FEM began in the early 1960s. Its development is not yet complete. Initially, FEM developed only for the mechanics of solid and flexible bodies. However, it has also been shown to be applicable to other classes of tasks such as: temperature field, gas and liquid flow, electricity and magnetism, radiation and mass transfer, coupled micro- and nanostructure analysis tasks, etc. [1-3] . Nowadays it belongs to the most universal, most widespread and most effective numerical methods of solving engineering tasks, resp. solving field tasks. Numerical methods transform a system of partial or ordinary differential equations (DE) describing a given task into a system of algebraic equations that is solved on a computer. The DE are built for an unknown field function (displacement, temperature, electrical potential ...) on a finite bounded continuous or multiply continuous area (line, area, volume) [4-6]. The unknown field can be scalar (temperature potential) or vector (deformation, velocity). The aim of DE is to find such a function dependent on the coordinates of the selected reference system so that it meets the initial and boundary conditions of the solution. By substituting coordinates of the selected point of the investigated area, the value of the "primary" unknown physical quantity at that point can be obtained from this function. With regard to the choice of substitute functions, FEM is an approximate method and its accuracy also depends on the fineness of discretization of the solution to finite elements and nodal points [7-9]. Finite elements typically have the shape of a line, area or volume of finite dimensions. The finer the finite mesh, the higher the accuracy of the solution. However, it must be said that even a very thick network often gives satisfactory and usable results. Networking of the area as well as possible network refinement takes place automatically. Today's PCs are able to solve large algebraic equation systems very efficiently at the level of ordinary PCs. Thus, the initial drawback of this method regarding the problems of solving large algebraic equation systems on the first low-power computers is eliminated.

\section{FEM analysis model}

In order to carry out the analysis, a computational model was created, an assembly consisting of volume parts. In the analysis, half symmetry is used to achieve the lowest computational time Contacts have been created considering the friction between the individual parts of the assembly. In the analysis, holes, shrinkage, and all parts that had no relevant effect on the assembly's stress were removed from the assembly. The bolted joints were replaced by beam members except for the bolted joint between the stand and the frame, where it was required to analyze the bolted joint. Friction contacts were formed between the screw heads and the surface on the stand, and fixed contacts were formed between the screw faces and the holes in the frame. Also, when placed on pins, a constraint was created with the rotation allowed around the pin axis.

\subsection{Load specification}

The axial and radial load of the sample is generated by the hydraulic cylinders of the station. The force arm is determined by the Frad and Fax values (Fig. 1). The specific test load conditions were as follows:

I. Case radial $15 \mathrm{kN}$, axial $10 \mathrm{kN}$ (current status)

II. Case radial $20 \mathrm{kN}$, axial $15 \mathrm{kN}$ (required status) 


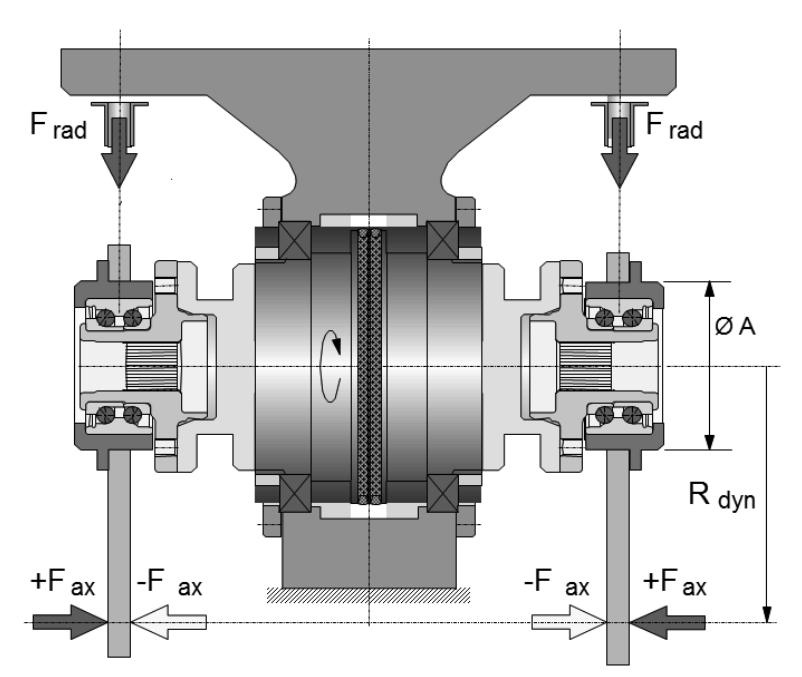

Fig. 1 Scheme of the design load of the test station

\subsection{Finite element mesh}

The modified assembly model was meshed using 10node quadrilateral SOLID 187 elements (Fig. 2) and 20node six-quadrilateral SOLID 186 elements (Fig. 3). The total number of elements is 535543 and the number of nodes is 2138321 .

E: Copy of Static Structural

Fixed Support

Time: $0.32375 \mathrm{~s}$

3/1/2019 11:50 AM

Fixed Support

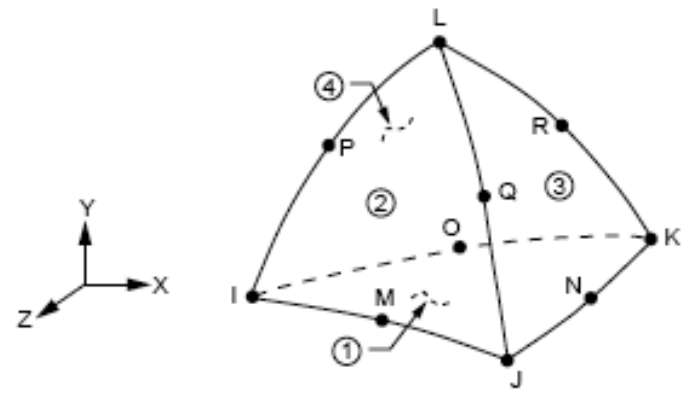

Fig. $23 D 10$ nodes element

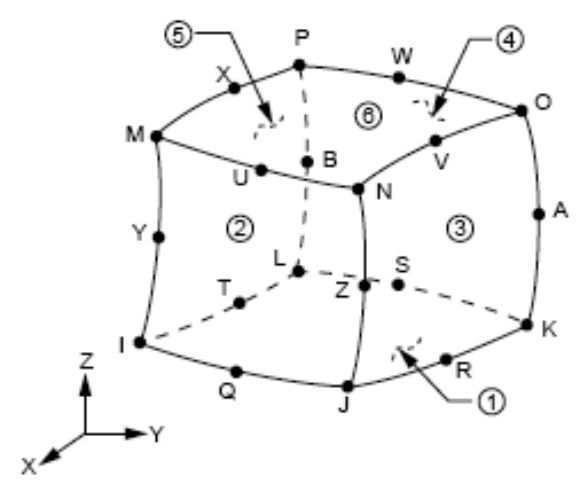

Fig. 33 D 20 nodes element

\subsection{Boundary conditions}

The boundary conditions take into account the location of the test station. All the degrees of freedom on the underside of the frame, marked in blue, have been taken to solve the given analysis (Fig. 4). 


\subsection{Prescribed loads}

For the test station, the loads have been prescribed according to the scheme in Fig. 1, where the loads are shown in radial and axial directions.

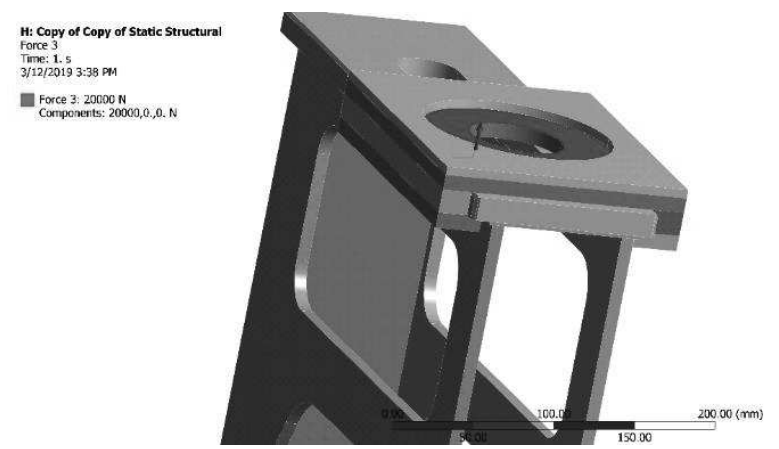

Fig. 5 Load of test station by radial load

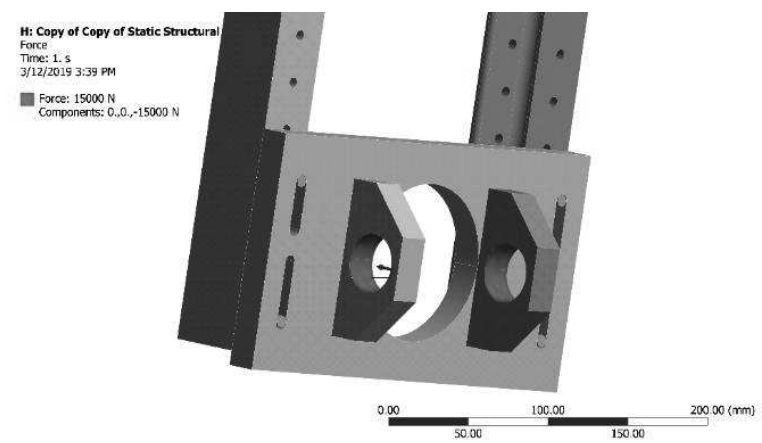

Fig.6 Load test station with axial load

\subsection{Material properties}

The test station is made of structural steel (yield strength $680 \mathrm{MPa}$ ). The material properties correspond to this type of steel: Young's modulus of elasticity E $=200 \mathrm{GPa}$ and Poisson number $\mu=0.3$.

\section{Evaluation of results}

The total load application time was 1 second for each load level with a constant time step.

This paper evaluates the distribution of Von Mises stress and deformation both on the whole test station assembly and on individual parts. Maximum stresses (peaks) have a singular character and are caused by sharp corners or edges eg. by passing between individual welded parts. This state of the stress concentrators (stress peaks) cannot actually occur. Therefore, these stresses are not included in the results of the numerical simulation.

\subsection{Load case 1}

The first load state is a state where the size of the radial force of $15 \mathrm{kN}$ and $10 \mathrm{kN}$ size axial force. On the flange, the stress value did not exceed the limit of 460 MPa (Fig. 8). At the stand, the values were at a level of $180 \mathrm{MPa}$ (Fig. 9). Next, the bolt connection between the stand and the frame was analyzed, where the critical stress level was not reached. As the last area of interest, the studs were investigated, where the tension did not increase.

\section{J: Static Structural \\ Equivalent Stress: \\ Type: Equivalent (von-Mises) Stress Unit: $\mathrm{MPa}$ \\ Time: 1 \\ 3/13/2019 7:39 AM

$1186.8 \mathrm{Max}$
400
350
-300
250
200
150
100
90
5.3675 e- 9 Mi
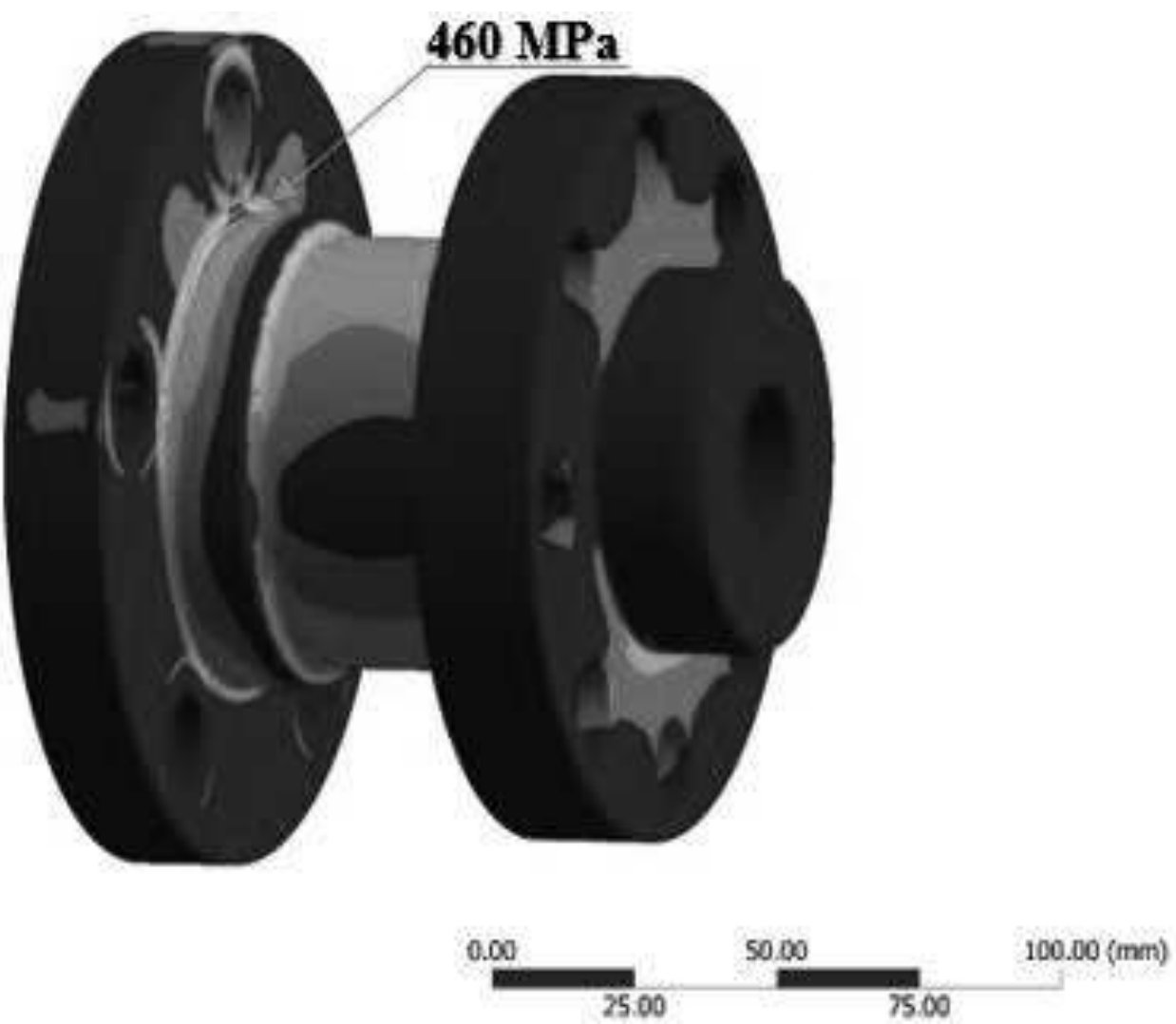

Fig. 7 Von Mises stress on the flange 


\section{3: Static Structural Equivalent Stress \\ Type: Equivalent (von-Meses) Stress Unit: MPa \\ Time: 1 \\ 3/13/2019 7:43 AM

$\mathbf{1 1 8 6 . 8}$ Max
150
131.25
112.5
93.75
75
56.25
37.5
18.75
$5.3675 e-9$ Min

\section{E: Copy of Static Structural} Equivalent Stress

Type: Equivalent (won-Mises) Stress Urit: $M 9 a$

Time: 1

$3 / 4 / 2019$ 10:51 AM

1451.9 Max
600
525
-450
375
300
225
150
75
$\mathbf{2 . 9 8 0 1 e - 9}$ Min

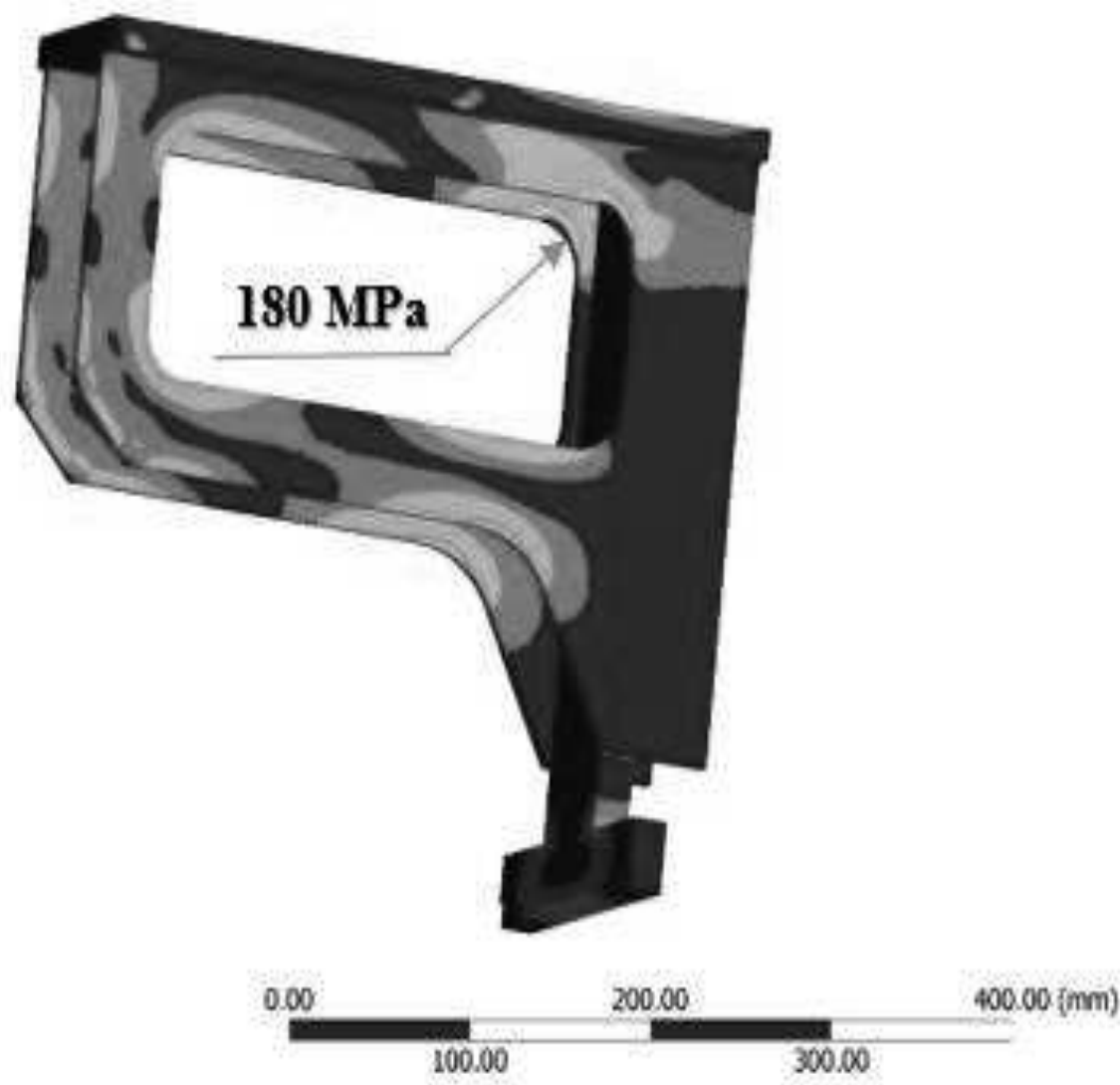

Fig. 8 Distribution of Von Mises stress on the stand
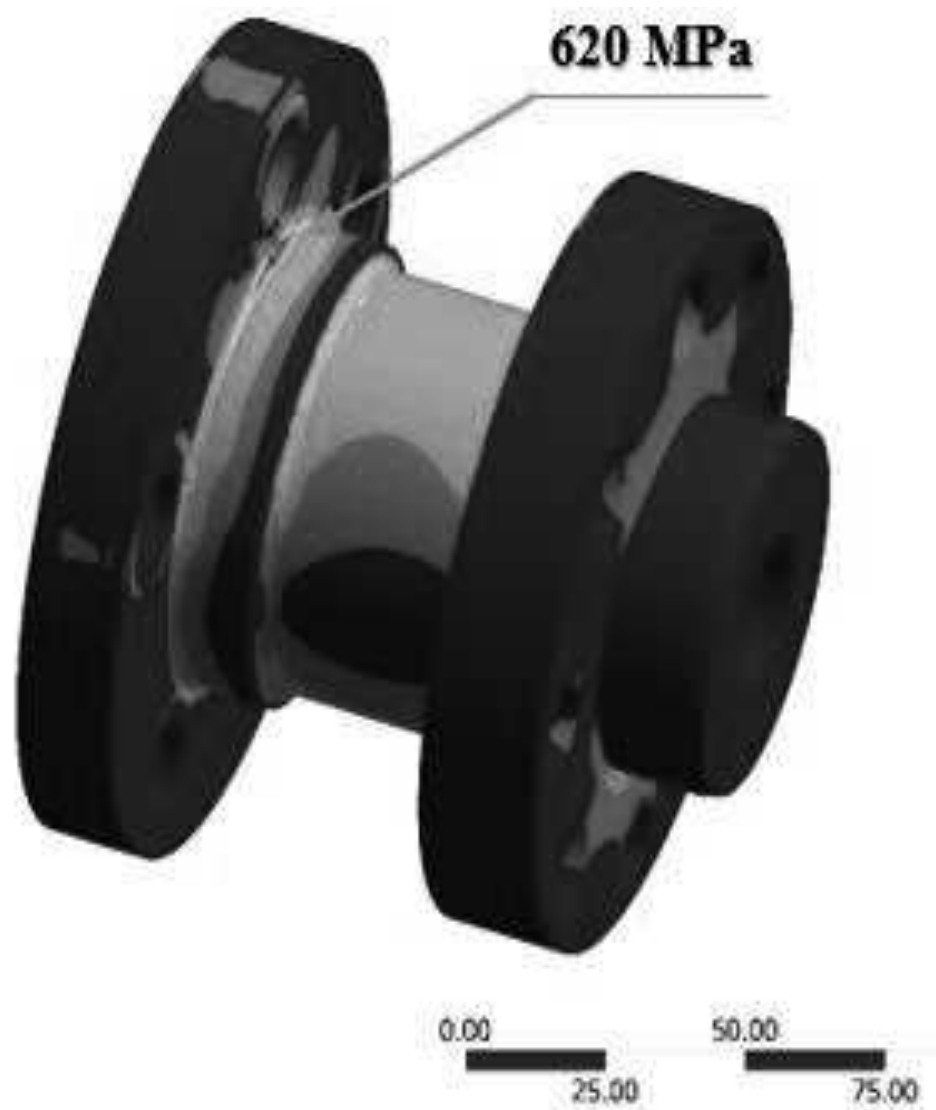

$100.00(\mathrm{~mm})$

Fig.9 Von Mises stress on the flange 


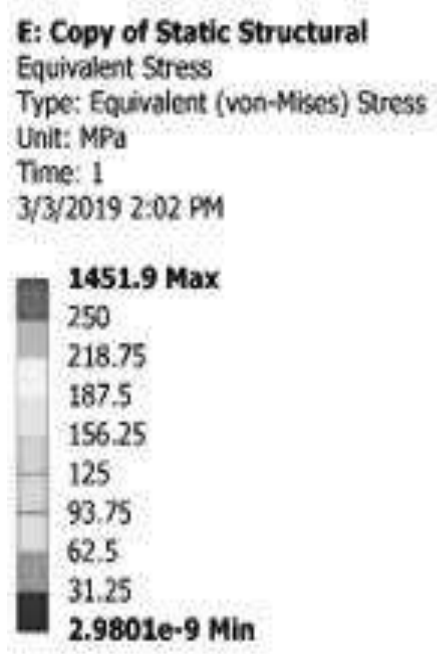

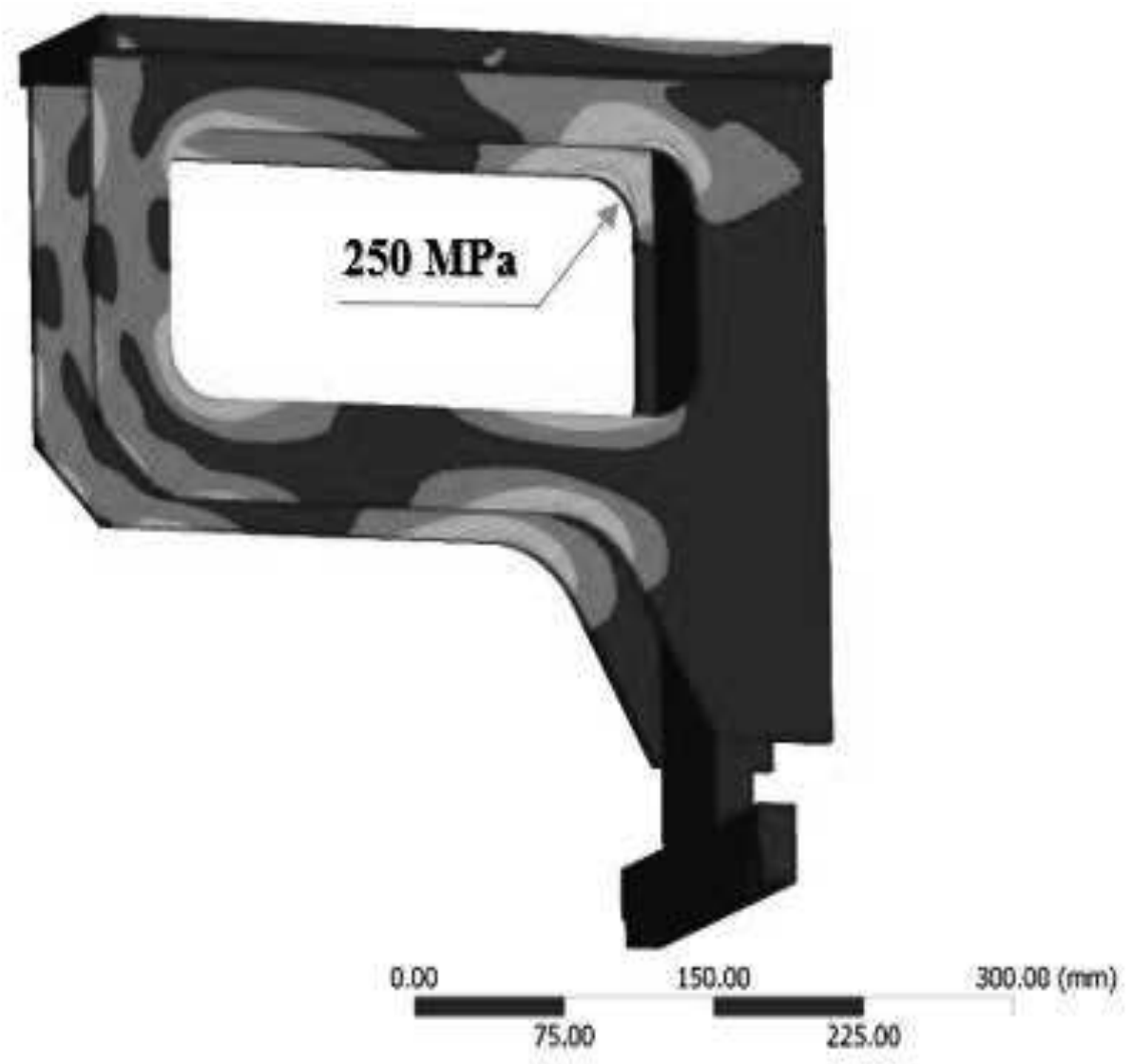

Fig. 10 Distribution of Von Mises stress on the stand

\subsection{Load case 2}

The second case will be when the radial force is $20 \mathrm{kN}$ and the axial force is $15 \mathrm{kN}$ (Fig. 1). As the magnitude of the forces increased compared to the load state 1 , the stress values in the same places increased on the flange and on the stand (Fig. 10,11). The flange tension value is about $620 \mathrm{MPa}$ (Fig. 10). On the stand the stress value increased to approx. $250 \mathrm{MPa}$ (Fig. 11).

\section{Conclusion}

The main objective of the FEM numerical simulations was to determine the locations of the maximum von Mises stresses and deformations that occurred on the analyzed mechanism of the test station under loading with prescribed loads according to the diagram in Fig. 1.

Overall, the analysis was performed for 2 load levels the first was for the current state, which represents $15 \mathrm{kN}$ radial load and $10 \mathrm{kN}$ axial load. In the second load state, the forces increased to $20 \mathrm{kN}$ radial load and $15 \mathrm{kN}$ axial load.

The analyzed assembly is made of structural steel, with appropriate finishing, which according to the client have a minimum yield strength of $680 \mathrm{MPa}$. The analyzed bolt connection between the frame and the stand consists of M10 bolts, which are made of steel with strength class 8.8 where the yield strength is $640 \mathrm{MPa}$.

The maximum stresses for the first load case, which were determined by numerical simulation on the analyzed assembly, occurred on the flange and their value is 460 MPa (Fig. 8). Further, the stresses and deformations on the stand, where the stress value is $180 \mathrm{MPa}$ (Fig. 9), were evaluated, on the screws connecting the frame of the assembly to the stand, the value was up to $150 \mathrm{MPa}$. The stress at the pins is up to $200 \mathrm{MPa}$.

In the second load case, the maximum stresses also occurred at the flange of $620 \mathrm{MPa}$ (Fig. 10). The stress values on the stand were $250 \mathrm{MPa}$ (Fig. 11), the tension on the screws stabilized at a value of up to $200 \mathrm{MPa}$. At the pins again the stress value remained at the level up to $200 \mathrm{MPa}$.

The maximum stress values that were found for the individual load cases were around $620 \mathrm{MPa}$. It follows that the maximum von Mises stresses did not exceed the yield strength of a given structural steel and the design under consideration satisfies the ultimate limit state for both types of loads.

\section{Acknowledgement}

The part of the results of this work was supported by grant KEGA 017ŽU-4/2017

\section{References}

[1] ŠUlKA, P., SAPIETOVÁ, A., DEKÝŠ, V., SAPIETA, M. (2017). Analysis and synthesis parameters influencing to the effects of impact. In: MATEC Web of Conferences, 157, art. no. 03018.

[2] SAPIETOVÁ, A., SÁGA, M., KURIC, I., VÁCLAV, Š. (2018). Application of optimization algorithms for robot systems designing, 
In: International Journal of Advanced Robotic Systems 15(1).

[3] DOMAŃSKI, T., SAPIETOVÁ, A., SÁGA, M. (2016). Application of Abaqus Software for the Modeling of Surface Progressive Hardening, In: Procedia Engineering, 177, pp. 64-69.

[4] NOVAK, P., DEKYS, V. (2015). Induction heating of inner rolling bearing ring in ANSYS, In: Manufacturing Technology, Vol. 15, No. 5, pp. 881-885.

[5] ŽMINDÁK, M., NOVÁK, P., DEKÝŠ, V. (2017). Analysis of bond behaviour in strengthened reinforced concrete beam with carbon fiber reinforced polymer lamella, In: MATEC Web of Conferences, 107, art. no. 00045, .
[6] SAPIETA, M., SAPIETOVA, A., DEKYS, V. (2017). Comparison of the thermoelastic phenomenon expressions in stainless steels during cyclic loading, In: Metalurgija, 56 (1-2), pp. 203-206.

[7] BITTNER, V., TUČEK, R., PANSKÁ, Š., SVOBODA, M., JELEN K. (2017). Using the Fourier Transform in the Analysis of Vibration Load Tests of Heterogeneous Mechanical Systems. In: Manufacturing Technology, Vol 17, No. 6, pp. 839-841.

[8] ASTARITA, A., PRISCO, U. (2017). Tensile Properties of a Hot Stretch Formed Ti-6Al-4V Alloy Component for Aerospace Applications. In: $M a-$ nufacturing Technology, Vol. 17, No. 2, pp. 141147.

[9] KOVÁCS, G. (2016). Productivity Improvement of Assembly Lines by Lean Methods. In: Manufacturing Technology, Vol. 17, No. 2, pp. 192-197. 